\title{
Optimisation of product portfolio sales and their risk subject to product width and diversity
}

\section{Tomasz Brzęczek ${ }^{1}$ (1)}

Received: 21 February 2018 / Accepted: 26 November 2018 / Published online: 7 December 2018

(c) The Author(s) 2018

\begin{abstract}
Prior research and theoretical studies claimed that a company extends offered product and commodities scope in order to make sales and profits grow, and the most important to decrease market risk. Others claimed that in some circumstances product category reduction leads to such results. So in our opinion every adjustment of product width and diversity should be called a diversification, if it achieves mentioned goals. In literature there is lack of methods of prediction and assessment of diversification effectiveness. To explore this issue we measure sales risk in terms of the expected error of sales forecast. We develop modern portfolio theory and forecasting theory to address their limitations in product portfolio analysis. We formulate a set of decision models, whose objective functions include different measures of an expected prediction error. We separately take it into consideration, whether to reduce or extend width of portfolio by one product category. Finally, we verify models using an agricultural production factors and equipment wholesaler's real sales data and sales forecasts for considered new product categories. Sales data are organised into samples for the evaluation of decision model parameters and for forecast testing. We have found that product expansion usually leads to business's higher forecasted sales and its nominal risk but also to lower relative risk. In our model any decision about product introduction or termination is assessed in relation to business's sales and their risk, unlike in popular financial methods of project or product investment performance and return assessment.
\end{abstract}

Keywords Sales forecasting · Portfolio theory $\cdot$ Product diversity decision · Product category $\cdot$ Risk analysis

JEL Classification C53 $\cdot$ C61 $\cdot \mathrm{L} 25 \cdot \mathrm{M} 21 \cdot \mathrm{M} 31$

Tomasz Brzęczek

tomasz.brzeczek@put.poznan.pl

1 Faculty of Engineering Management, Poznan University of Technology, Strzelecka 11, 60-965 Poznan, Poland 


\section{Introduction}

We consider the product portfolio analysis that has arisen in the management literature in the context of strategic management and marketing, and so far it has gained wide acceptance among managers of diversified companies (Jugend and da Silva 2014; Mallin and Finkle 2011). It was initially used mainly to analyse the effect of product innovations on firms' competitive positions. Nowadays continuation of this approach is product portfolio management (PPM) that aims to support companies with regard to making a business strategy viable, optimizing resources, minimising risks, and reducing the time to market in new product development (NPD) according to Jugend et al. (2016). If analysis is focused on process of new product development (NPD), called also "new product portfolio" or "R\&D portfolio", or is focused on another processes like IT projects, organizational change projects or infrastructure projects the same abbreviation PPM is used to mean project portfolio management (Voss 2012). This paper concerns first, wider meaning of PPM that is product portfolio management and business range decisions (Cooper et al. 1999). We argue that in minimisation of business's risk, both, new products' risks and present products' risks should be taken into account, and we propose an appropriate decision model of simulated product portfolio, its forecasted sales and the risk of their realisation as measure of business's risk on the markets. Our model is dedicated for companies in which the most important issue is product categories conglomeration that controls for markets' risks and consumers' acceptation. Concerned question is about what kinds of products to offer. Rosenbloom (1980) argued that strategic market planning implies the use of fairly sophisticated planning methods as portfolio analysis for defining business in terms of product category conglomeration. This problem in the wholesales context remains of our interest in this paper. Retailers and services companies face discussed issue. Conglomeration problem is more important than product improvement and development or resources and inputs allocation in many old economy industries' corporations running many strategic business units or multi-product portfolio. Therefore we applied our decision model of portfolio sales and their risk optimisation at a large wholesaler specializing in agricultural equipment and spare parts, but also offering a broad range of household and garden items, and non-core product categories (i.e., toys, pet accessories and food). Especially, we formulate models of a product category reduction or expansion decision that optimize product portfolio's sales in the future and their risk. To formulate those models were used approaches of modern portfolio theory (MPT) and forecasting theory.

Marketing focuses on a company's product scope complementarity that meets clients' needs and is a competitive offer on the market. A time-constrained consumer that prefers one-stop and multi-product shopping puts pressure on retailers to broaden their assortment with different product categories and even noncore product categories (Ailawadi and Keller 2004; Hruschka 2017). Marketing research studies provide recommendations for a process of cross-category assortment extensions. By introducing a series of closely related but increasingly 
distant extensions, very different product categories should be introduced (Mantrala et al. 2009; Meyvis and Janiszewski 2004). We can observe supermarkets selling a very wide scope of products, including household items or even gasoline (Ma et al. 2011). However, modelling of the product category reduction or expansion and its influence on total sales level and their volatility have received little attention so far (Wan et al. 2014).

Sales profitability and volatility owing to product decisions were analysed in assortment planning on the product level, otherwise known as product assortment or assortment depth (Hart and Rafiq 2006), which is the process conducted by a retailer to determine the number and types of products in a line (Rajaram 2001), or product variety planning, which is about determining the number of style and colour combinations within a specific product group, corresponding broadly to the number of 'models, otherwise known as stock keeping units (SKUs) (Vaagen and Wallace 2008).

We find these works methodologically useful for us, because they introduced the modern portfolio theory approach into assortment selection and variety planning decisions under risk. Their conclusions are also interesting for our theme of product conglomeration. Also the works regarding sales time series and their volatility modelling are considered in our paper to define variables and formulate our decision model (Gorman and Brannon 2000; Sloot et al. 2006).

The rest of the paper is organized as follows. In Sect. 2 we highlight existing works that provide us with applications of the modern portfolio theory to sales and their risk modelling. In Sect. 3 we introduce new sales and their risk optimisation decision models. These models allow us to study the structure of product categories' sales and their risk, taking into account trend, seasonality and competition forces. Empirical data are presented in Sect. 4. Analysis resulted with sales predictions and their risk estimates for simulated portfolio's product scopes. Models' results and their verification are given in Sect. 5. Section 6 provides discussion of findings. Section 7 provides concluding remarks.

\section{Literature review}

Product portfolio management (PPM) is the theory of product decision making in the company. According to many researchers consensus PPM performance should be assessed concerning three main objectives (Jugend and da Silva 2014; Killen 2017; Oh et al. 2012):

1. Strategy alignment: Selection of current and future product lines in order to pertain to business strategy and make it viable.

2. Balance: The establishment of the mix of product projects considering the expected risks and rewards associated with the development of these projects.

3. Maximized portfolio value: The most efficient use of resources input in product projects. There is also additional objective 4 (Voss 2012):

4. Future preparedness. Project results can offer value that is realized in the future. 
The most popular methods of portfolio value maximization in businesses are financial methods (NPV, IRR, options pricing). These methods are popular among managers owing to easy accessible financial data and precise analytical concept of risk measures (Cooper et al. 1999; Jugend et al. 2016). However, products' and projects' risks are treated separately and it is tough to balance them for portfolio. Research on big sample surveys of business units shows that popular financial methods usage resulted with lower performance and especially lower return performance in comparison to other methods (Cooper et al. 1999; Jugend et al. 2016). The same research has brought conclusion that using financial methods in combination with strategic alignment techniques and market research information leads to better overall performance of PPM. Our decision model is to be such method that combines mentioned objectives of PPM. Models are appropriate for businesses that operate mostly on mature markets for which the main risk comes from market fluctuations of portfolio sales that cannot be forecasted but can be lowered or lowered in relation to sales. Models seem to be less relevant to high-tech businesses as they don't cover for risk of $\mathrm{B}+\mathrm{R}$ projects feasibility and their technological innovativeness. Products or retail formats conglomeration usually leads to higher sales, value and lower risk (Gerchak and He 2003; Hassanzadeh et al. 2014; Kim et al. 2016). Therefore, Dekimpe et al. (2011) consider a multi format portfolio and expanding of portfolio width as the main challenges in retailing. Modelled issue pertains usually retailers and wholesalers very few of whom, called category killers, offer one product category with very deep assortment.

In operations management Jacobs and Swink (2011) find out that diversification that raises product portfolio complexity results in higher sales volatility that leads to a raise in operational costs. Jacobs and Swink (2011: 686) argue that "aggregate sales volatility mediates the effects of diversity on a) fixed assets utilization and b) operational performance". However, our model results show that higher sales risk is symptom of wider diversity in product portfolio but it doesn't always mean higher complexity. Ton and Raman (2010) explain that as a company's product variety increases, so too do errors in demand forecasting and information systems resulting with higher operating costs, especially stock keeping costs. Our model balances higher market sales for wider portfolio with their risk and its cost. Therefore in objective functions we used measures of expected error of predicted sales as proxy for risk and cost connected to it. In two of our models portfolio's sales forecast value and its error are jointly optimised to carry with second and third objectives of PPM. Optimisation of net value of portfolio is identified with profit that is a difference of sales and risks' costs, especially costs of safety stock. Other objectives of PPM can be handled by rationale analysis of models' solutions.

Our model of sales and their risk optimisation in product portfolio diversification decision is developed from financial methods of risk measurement and analysis, especially modern financial portfolio theory. Markowitz (1959) proposed the following model of the securities portfolio risk minimisation:

$$
\begin{array}{r}
\text { minimize } \boldsymbol{x}^{\prime} \boldsymbol{V} \boldsymbol{x}, \\
\text { subject to: } \\
\mathbf{1}^{\prime} \boldsymbol{x}=1, \\
\boldsymbol{x} \geq \mathbf{0},
\end{array}
$$


where $\boldsymbol{x}=\left[x_{i}\right]_{I \times 1}$-the column vector of stock shares in a portfolio, an element in row $i$ is a share of stock $i$ from a number of $I$ stocks, and $\boldsymbol{x}^{\prime} \mathrm{s}$ a transposition of vector $\boldsymbol{x}$,

$\boldsymbol{V}=\left[\operatorname{cov}_{i j}\right]_{I \times I}=\left[\rho_{i j} \sigma_{i} \sigma_{j}\right]_{I \times I}$ the matrix of stocks pairs covariance of return rates, where $\operatorname{cov}_{i j}$ is a covariance between stock $i$ and stock $j$ from a number of $I$ stocks, and $\rho_{\mathrm{ij}}$ is a correlation coefficient,

$\mathbf{0}$ and $\mathbf{1}$-column vectors with the number of $I$ zeros and the number of $I$ units respectively.

The risk in the model is defined by the variance of the random returns of investments and their portfolios. Risk decreasing is possible owing to a lack of perfect positive correlation of return rates of securities, which takes place if any correlation coefficient has a level below one. The smaller the coefficient, the more risk can be diversified, and the entire risk can be diversified if the correlation is perfectly negative.

Vaagen and Wallace (2008: 435) argue, "Despite the significance of the mean-variance theory in financial portfolio building, it has not been directly used for industrial product variety problems". We can add that we find only a few papers cited above about portfolio theory application for product width modelling. Modern portfolio theory (MPT) and the mean-variance (M-V) analysis have been applied in retailing literature to find bullwhip effect, that is how the volatility of the industrial product line content and long supply chains contribute to the uncertainty that retailers face (Goto 2008; Mantrala et al. 2009). They find that the best solution is a postponed ordering strategy that allows for a reduced retailer, and further reduced supply chain, demand variability, but also means that producers have to bear more risk of costs.

Direct application of the modern portfolio theory has been used by Brown (2010) to manage profitability of the retail format portfolio. Brown (2010) describes the limitations of direct applications and in particular the assumption of independence of formats' sales and returns. He argues that a number of portfolio components and their amount and share not only affect portfolio results, but also are dependent on each other. This means that a company's manager can decide what retail formats or what products to sell and what their maximum quantities a company's capacity allows to supply. However, the last decision is connected to the expected market sales amount and quantities that depend on a company's resources and competition on its products' markets. Market and demand risk is really connected with selection of appropriate product categories to be sold and abilities to predict market sales. Our model captures this decision context, unlike the financial investment portfolio model, in which allocations across investment alternatives are independent, although their returns are dependent. So the model provides a mean-variance method to analyse sales hedging due to product category reduction or expansion.

Our model has to assess the expected error of sales, so it takes into account random, residual sales volatility that occurs in the market, as Gorman and Brannon (2000) recommend. These residual sales are estimated in econometric models separately from seasonality and trends in sales time series. Akkerman and 
van Donk (2009: 2) find that "variability in the product mix causes short term imbalance" and "seasonal demands and new product introductions can result in products which have demand that is positively or negatively correlated with the demand for other products." There are also some alternative methods to estimate random sales covariance due to product competition and prices. Bandyopadhyay (2009) models them using BVAR and seasonal dummy variables. Mehta (2007) also models cross-category competition, although from the point of view of the consumer that makes a basket choice. He uses a logit model and faces the problem when aggregates data and estimates sales.

Sloot et al. (2006) study a similar problem of assortment reduction in product category using single equation econometric modelling. Cadeaux and Yee (2013) developed a structural multi equation model of category sales volatility and heterogeneity impact on category assortments and performance. Our portfolio model of sales is comprehensive because it works with any method that gives estimates of standard product categories' residual sales and their covariances.

Product assortment planning is the last research stream related indirectly to the product variety in a portfolio. Its objective is usually profit maximisation subject to resource allocation in production (Rajaram 2001). Trappey et al. (1993) apply modern portfolio theory to manage the profitability risk of merchandise in retailing. The product assortment and its deepness is usually concerned. However, some research studies consider the impact of a product variety on sales risk. Many of those studies address risk issues in the single-item newsboy problem; hence they are not directly applicable for studying product variety or product diversity impact on risk (Agrawal and Seshadri 2000). Multi-item newsboy type models, for the so-called newsstand problem, can be viewed as assortment planning models for a given variety (Haksever and Moussourakis 2005). The closest to our issues is study by Vaagen and Wallace (2008) in which they use sales correlation coefficients of stock keeping units in two uncertain states of the world that simulates a bi-modal distribution of demand. However, instead simulated sales our study concerns empirical research of many product categories' sales correlations and additionally answers how to model their impact on product portfolio sales and their risk. Our models are also unique because product diversity is directly modelled with decision variables of products' choices not with products' quantities as usually in assortment planning. Hence, risk objective functions change dynamically in time thanks to their link with sales time series' observations and forecasts. This is advantage in comparison to assortment optimization models that include demand limits for production and sales quantities only in constraints limits calculated separately for each period. In known models impact of product width on business' sales is ignored, if it is not connected to constraints on resources that are inputs to production. We model also impact of known concept of safety stock costs on business's and especially product distributor's sales profitability. 


\section{Model formulation}

In this section, the application of portfolio theory is proposed in order to model and predict the impact of category reduction or expansion on sales and on their risk and profitability. The model is feasible for the following assumptions:

1. A company supplies at least two product categories if decision about product category reduction is to be optimised.

2. A company's historical sales time series for every offered product category are treated as a proxy for demand quantity multiplied by price asked by a company. This is true under the condition that the company always keeps sufficient safety stock to meet surplus of demand over planned supply at a price asked by the company. For the considered new product categories a partial of historical whole market sales can be used for the company's hypothetical sales results. Real and hypothetical sales time series should be deflated with price index to constant value of money in time.

3. The expected value of a company's product category sales is predicted from empirical econometric models, estimated for time series of sales observations. These theoretical values are treated as a proxy for planned supply quantity at the company's price.

4. Residual sales and their standard deviation represent historical errors in sales forecasting and supply planning. Positive residual sales are symptoms of sales from stock and a possibility to increase supply or a company's price for the next period. Negative residual sales occur when current sales are lower than the expected one, and some part of supply is not sold and makes stocks value to grow and/or the price lowered. Positive correlation of residual sales represents complementary product categories and negative correlation represents substitutable product categories. Therefore, pricing is involved in data and sales parameters, but prices are not decisive variables of our models.

5. The trend, seasonality and residual sales are independent from each other for each product category. Accurate methods of econometrics of time series should be used to estimate sales parameters and residual sales.

Notation in our Models (1-6) presented in Table 1 is as follows:

1. Sets:

$I_{1}$ - set of product categories, called the starting portfolio, that have been offered by a company till a decision about category reduction or expansion, product categories are indexed by $i, j=1,2, \ldots I$.

$I_{2}$ - set of new product categories considered to be offered, those product categories are indexed by $i, j=I+1, I+2, \ldots I, \ldots, I+m$.

2. Variables: 


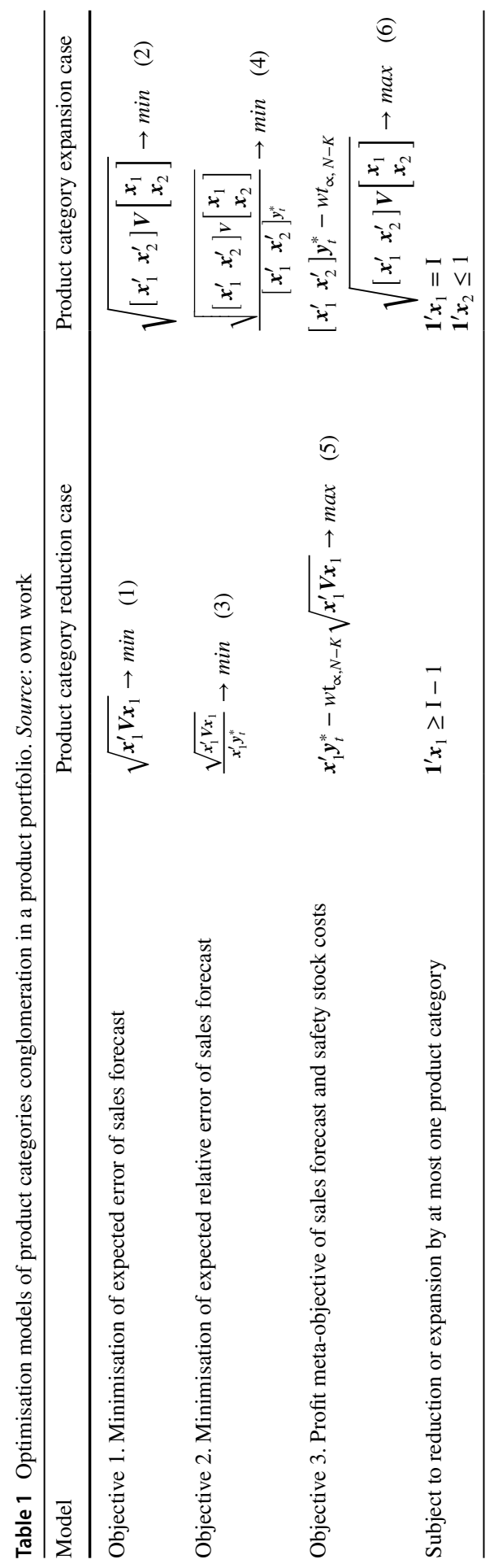


$x_{i} \in\{0,1\}$-dummy decision variable, for which value 0 means that product category $i \in I_{1}$ is reduced in a company's portfolio or product category $i \in I_{2}$ is not introduced into the portfolio, and value 1 means that offering of product category $i \in I_{1}$ is to be continued or product category $i \in I_{2}$ is introduced into the portfolio,

$\boldsymbol{x}_{\mathbf{1}}$ - column vector of dummy decision variables $x_{1}, x_{2}, \ldots, x_{I}$, and $\boldsymbol{x}_{\mathbf{1}}{ }^{\prime}$ refers to its transposition to a row,

$\boldsymbol{x}_{\mathbf{2}}$ - column vector of dummy decision variables $x_{I+1}, x_{I+2}, \ldots, \mathrm{x}_{I+m}$, and $\boldsymbol{x}_{\mathbf{2}}{ }^{\prime}$ refers to its transposition to a row.

\section{Parameters:}

$y_{i t}{ }^{*}$ - the forecasted expected value of sales of category $i$ in period $t$,

$\boldsymbol{y}_{\boldsymbol{t}}{ }^{*}=\left[y_{i t}{ }^{*}\right]$ —column vector of sales forecasts in period $t$ for product categories $i \in I_{1}$ in case of product category reduction or $i \in\left\{I_{1} \cup I_{2}\right\}$ in case of product category expansion,

$s_{i}$ - standard deviation of residual sales for category $i$,

$p_{i j}$-correlation coefficient between residual sales of category $i$ and category $j$,

$\boldsymbol{V}$-variances and covariances matrix for residual sales of product categories, in case of product category reduction analysis $\boldsymbol{V}=\left[v_{i j}=p_{i j} s_{i} s_{j}\right]_{I \times I}$, for product expansion $\boldsymbol{V}=\left[v_{i j}=p_{i j} s_{i} s_{j}\right]_{(I+m) \times(I+m)}$,

$t_{\alpha, N-K}-t$-Student's critical value for a right side of distribution and for assumed symmetrical level of significance $\alpha$, and $N-K$ degrees of freedom in a sample of product categories' sales $N$ observations and $K$ parameters in a model from which residual sales are calculated,

$w$-average cost of safety stock needed to supply one currency unit of sales forecast error with probability $1-\alpha / 2$ that is called an inventory service level (Chen and Krass 2001; Radasanu 2016).

Using the previously defined symbols we formulate optimisation models for both cases of reduction and expansion of product category with three different objective functions for each decision case in Table 1.

Models (1)-(2) in Table 1 have objective functions that are explained as estimates of expected error of product portfolio sales or at least lower limit of this error. In models (3)-(4) objective functions are estimates of relative errors of total sales forecasts that can be compared between product portfolios, whose product varieties and sales forecasts differ. In models (5)-(6) we take into account that a company could be interested in the maximisation of expected profit, so we maximise a meta-objective of expected profitable sales that constitute the surplus of sales expected forecast over costs of safety stock keeping. The costs of safety stock keeping are the function of an estimate of expected error of sales forecast that depends on product variety and product selection decision variables, but also on cost coefficient $w$ and an assumed inventory service level. In data research, we assumed that cost coefficient level equals 1 and that inventory service level equals $1-\alpha / 2=0.975$. Parameters $I$ and $m$ are finite and integer numbers of the considered product categories, so preview of all feasible solutions can be and is used in this paper to solve formulated optimisation models. 


\section{Data source and parameters estimation}

We applied formulated models at a large wholesaler specializing in agricultural equipment and spare parts, but also offering a broad range of household and garden items, and non-core product categories (i.e. toys, pet accessories and food). The analysed company supplied 150 of its own retailers and 1949 total retailers during the years 2005-2011. In 2012 a merger of the company with its competitor took place and that is why further sales data is not comparable. The company offered over 39,000 products, from which 24,000 were included in its everyday offer. We analysed quarterly sales in Polish zloty currency. Quarterly data include typical seasonality for agriculture. Product sales are split into the following 10 product categories, that constituted product width offered unchanged during all analysed years:

$i=1$ : Power transmission (drive shafts, bearing and housings, fasteners and seal rings, belt drives and pulleys, chain and accessories, geared motors and gearboxes, shaft couplings);

$i=2$ : Professional clothing, toys and leisure (shoes, boots, gloves, first aid and safety kits, books, puzzles, models, outdoor and winter toys, go-carts);

$i=3$ : Machines and equipment for harvesting and transport (combines, lawn movers);

$i=4$ : Tractor and vehicle parts (lighting, cab and truck bodies, suspension, brakes, engines and others);

$i=5$ : Tools and workshop equipment (grinding, abrasives, tools);

$i=6$ : Machines and equipment for sowing, cultivation and protection (drilling, tillage and sprayer parts);

$i=7$ : Grass and feeding parts;

$i=8$ : Foodstuff and equipment for horses and pets;

$i=9$ : Hydraulics;

$i=10$ : Wheels and tyres for agricultural and non-agricultural machines.

Additionally we assumed that due to the company's market position and national range it could have achieved sales of 1 per cent of value of domestic production of each considered new product category according to monthly public statistics aggregated to quarterly series (Statistics Poland 2005-2011; Statistics Poland 2012: 41, 128):

$i=11:$ Nitrogenous fertilizers;

$i=12$ : Phosphoric fertilizers;

$i=13$ : Potassic fertilizers;

$i=14$ : Three of the above types of fertilizers together.

In a first step, sales time series in Polish zloty were deflated with CPI. Conducted tests of time series autocorrelation and the unit root test of stationarity (ADF, KPSS) gave contradictory conclusions. 
Therefore for each product category sales time series three models were estimated in the sample of quarters 2005-2010. Those three models were estimated by using three different methods in econometrics programme:

(1) linear trend with autoregressive lagged regressor of sales and additive seasonality,

(2) ARIMA of sales differences and seasonal differences of order for which sales time series were verified to be stationary in both stationarity tests,

(3) Winters' smoothing model with moving average, moving trend increment and additive seasonality, in which constants of smoothing were optimised to minimise RMSE.

From those three models for each category's sales we chose the best one. The one that has the smallest root of square mean error, called RMSE, of forecasts in testing sample of quarterly sales in year 2011.

Models with the most accurate forecasts were chosen because modern portfolio theory is a forward-looking normative approach that should be applied with forecasted returns and risk. However, past behaviour is one of the predictors of future results and, therefore, using historical data to calculate dynamic models of time series, it is not inappropriate in implementing portfolio theory (Bodie et al. 2009).

Subsequently, the parameters needed to solve optimisation models in Table 1 were calculated from the best chosen models for all fourteen product categories. These parameters are residual sales variances and covariances in matrix $\boldsymbol{V}$ and vector $\boldsymbol{y}_{t}^{*}$ of sales forecasts. Instead matrix $\boldsymbol{V}$ we present in Table 2 the correlation

Table 2 Symmetrical matrix of product categories' $i$ and $j$ residual sales correlation coefficients $\rho_{i j}$, and the last column of quarterly standard deviations $s_{i}$. Source: own calculation

\begin{tabular}{|c|c|c|c|c|c|c|c|c|c|c|c|c|c|c|c|}
\hline \multirow{2}{*}{$\begin{array}{l}\rho_{i j} \\
i=\end{array}$} & \multicolumn{14}{|c|}{ Product category $j=$} & \multirow[t]{2}{*}{$s_{i}$} \\
\hline & 1 & 2 & 3 & 4 & 5 & 6 & 7 & 8 & 9 & 10 & 11 & 12 & 13 & 14 & \\
\hline 1 & 1 & & & & & & & & & & & & & & 543,128 \\
\hline 2 & 0 & 1 & & & & & & & & & & & & & 438,540 \\
\hline 3 & 0 & 0 & 1 & & & & & & & & & & & & 394,006 \\
\hline 4 & 0 & 0 & 0.55 & 1 & & & & & & & & & & & 911,492 \\
\hline 5 & 0 & 0 & 0 & 0 & 1 & & & & & & & & & & 861,999 \\
\hline 6 & 0 & 0 & 0.50 & 0.37 & 0.46 & 1 & & & & & & & & & 733,971 \\
\hline 7 & 0 & 0 & 0 & 0 & 0 & 0 & 1 & & & & & & & & 354,055 \\
\hline 8 & 0 & 0 & 0 & 0 & 0.38 & 0.42 & 0 & 1 & & & & & & & 134,217 \\
\hline 9 & 0 & 0 & 0 & 0 & 0 & 0 & -0.37 & 0 & 1 & & & & & & 172,199 \\
\hline 10 & 0 & 0 & 0 & -0.33 & 0 & 0 & 0 & 0.33 & 0 & 1 & & & & & 181,768 \\
\hline 11 & 0.34 & 0 & 0 & 0 & 0 & 0 & 0 & 0 & 0 & 0 & 1 & & & & 222,961 \\
\hline 12 & 0.57 & 0 & 0 & 0 & 0 & 0 & 0 & 0 & 0 & 0 & 0.38 & 1 & & & 127,903 \\
\hline 13 & 0.46 & 0 & 0 & 0 & 0.37 & 0 & 0 & 0.49 & 0 & 0 & 0.71 & 0.59 & 1 & & 83,308 \\
\hline 14 & 0.46 & 0 & 0 & 0 & 0.34 & 0 & 0 & 0 & 0 & 0 & 0.81 & 0.57 & 0.79 & 1 & 281,144 \\
\hline
\end{tabular}

Coefficients insignificant at symmetrical $p$ value $=0.2$ level are replaced with zeros 
coefficients for residual sales of all pairs of product categories and standard deviations of all 14 product categories. Values lower than 0.30 were insignificant at 0.2 probability and replaced with zeros.

\section{Preview of solutions of sales and their risk optimisation models}

In Table 3, we present calculations of standard deviation of residual sales for analysed reduced product portfolios (1)-(10), for the starting portfolio of the company (11) and for expanded portfolios (12)-(15).

We found that, in general (with exclusion of categories 9 and 10), one product category reduction results with lower sales forecast and its lower error, and consistently one product category expansion results with higher sales forecast and its higher error. Reduction of each of above mentioned two categories 9 and 10 would raise slightly the expected forecast error and would lower the sales forecast. Reducing any of them would be ineffective in terms of all three goals of diversification: sales forecast, its expected error and its relative expected error. Among the offered product categories, category 6 is the most stimulating sales forecast error. However, this category is one with the second to the highest sum of quarterly sales and has the highest sales forecast in third quarter of 2011 quarters testing sample. Among the considered new product categories, category 14 is the most stimulating sales

Table 3 Preview of feasible solutions of model (1): portfolios (1)-(11) and feasible solutions of model (2): portfolios (11)-(15) of minimisation of standard deviation of residual sales. Source: own calculation

\begin{tabular}{|c|c|c|c|c|c|c|c|c|c|c|c|c|c|c|c|}
\hline \multirow[t]{3}{*}{ Portfolio no. } & \multicolumn{14}{|c|}{$x^{\prime}=\left[\begin{array}{ll}x_{1}^{\prime} & x_{2}^{\prime}\end{array}\right]$} & \multirow{3}{*}{$\begin{array}{l}\sqrt{x^{\prime} V x} \rightarrow \min \\
\text { [zloty] }\end{array}$} \\
\hline & \multicolumn{10}{|c|}{$\overline{x_{1}^{\prime}=}$} & \multicolumn{4}{|c|}{$x_{2}^{\prime}=$} & \\
\hline & $x_{1}$ & $x_{2}$ & $x_{3}$ & $x_{4}$ & $x_{5}$ & $x_{6}$ & $x_{7}$ & $x_{8}$ & $x_{9}$ & $x_{10}$ & $x_{11}$ & $x_{12}$ & $x_{13}$ & $x_{14}$ & \\
\hline 1 & 0 & 1 & 1 & 1 & 1 & 1 & 1 & 1 & 1 & 1 & - & - & - & - & $2,112,042$ \\
\hline 2 & 1 & 0 & 1 & 1 & 1 & 1 & 1 & 1 & 1 & 1 & - & - & - & - & $2,136,210$ \\
\hline 3 & 1 & 1 & 0 & 1 & 1 & 1 & 1 & 1 & 1 & 1 & - & - & - & - & $1,978,568$ \\
\hline 4 & 1 & 1 & 1 & 0 & 1 & 1 & 1 & 1 & 1 & 1 & - & - & - & - & $1,773,354$ \\
\hline 5 & 1 & 1 & 1 & 1 & 0 & 1 & 1 & 1 & 1 & 1 & - & - & - & - & $1,828,514$ \\
\hline 6 & 1 & 1 & 1 & 1 & 1 & 0 & 1 & 1 & 1 & 1 & - & - & - & - & $1,663,412$ \\
\hline 7 & 1 & 1 & 1 & 1 & 1 & 1 & 0 & 1 & 1 & 1 & - & - & - & - & $2,162,200$ \\
\hline 8 & 1 & 1 & 1 & 1 & 1 & 1 & 1 & 0 & 1 & 1 & - & - & - & - & $2,133,355$ \\
\hline 9 & 1 & 1 & 1 & 1 & 1 & 1 & 1 & 1 & 0 & 1 & - & - & - & - & $2,184,218$ \\
\hline 10 & 1 & 1 & 1 & 1 & 1 & 1 & 1 & 1 & 1 & 0 & - & - & - & - & $2,194,471$ \\
\hline 11 & 1 & 1 & 1 & 1 & 1 & 1 & 1 & 1 & 1 & 1 & 0 & 0 & 0 & 0 & $2,180,759$ \\
\hline 12 & 1 & 1 & 1 & 1 & 1 & 1 & 1 & 1 & 1 & 1 & 1 & 0 & 0 & 0 & $2,210,829$ \\
\hline 13 & 1 & 1 & 1 & 1 & 1 & 1 & 1 & 1 & 1 & 1 & 0 & 1 & 0 & 0 & $2,202,558$ \\
\hline 14 & 1 & 1 & 1 & 1 & 1 & 1 & 1 & 1 & 1 & 1 & 0 & 0 & 1 & 0 & $2,206,439$ \\
\hline 15 & 1 & 1 & 1 & 1 & 1 & 1 & 1 & 1 & 1 & 1 & 0 & 0 & 0 & 1 & $2,267,162$ \\
\hline
\end{tabular}

Minimum standard deviation of residual sales for reduction decisions is in bold and for expansion decisions is italicized 
forecast error. This considered new product category has the highest sales forecast as it consists of three other considered categories. Therefore, we find that the higher the sales the higher the forecast error. Hence, to compare risk of portfolios with different expected or forecasted sales we propose to use relative expected forecast error not the absolute one.

Table 4 includes the calculations of relative expected forecast errors for feasible solutions of product category reduction decision and product category expansion decision. Once again, product category 6 is the most stimulating for sales per cent forecast error and it should be reduced, if relative forecast error is minimised. However, the relative error of sales forecast can be lowered by reducing a product category in case of selection one from only two product categories that are categories 4 and 6. Reduction of any of them, would lead to a decline in relative error for a forecast. Such a decision lowers sales and demand risk. We should notice that categories 3-6 are product categories of the same industry that are complementary to main business's customers, i.e. farmers cultivating crops. These product categories constitute the core business that is horizontally diversified. Hence, the company instead to reduce fully product category 6 should cut its product assortment depth and length or introduce some products availability only to order. These are 4 out of 10 offered product categories and each of them makes a portfolio more horizontally diversified. Reduction of each of them would lead to less horizontally diversified portfolio. In case of product categories 4 and 6 , the reduction of each of them leads

Table 4 Preview of feasible solutions of model (3): portfolios 1-11 and feasible solutions of model (4): portfolios 11-15 of minimisation of relative expected forecast error. Source: own calculation

\begin{tabular}{|c|c|c|c|c|c|c|c|c|c|c|c|c|c|c|c|c|c|c|}
\hline \multirow[t]{3}{*}{ No. } & \multicolumn{14}{|c|}{$x^{\prime}=\left[\begin{array}{ll}x_{1}^{\prime} & x_{2}^{\prime}\end{array}\right]$} & \multirow{2}{*}{\multicolumn{4}{|c|}{$\frac{\sqrt{x^{\prime} V x}}{x^{\prime} y_{t}^{*}} * 100 \% \rightarrow \min$}} \\
\hline & \multicolumn{10}{|c|}{$x_{1}^{\prime}=$} & \multicolumn{4}{|c|}{$x_{2}^{\prime}=$} & & & & \\
\hline & $x_{1}$ & $x_{2}$ & $x_{3}$ & $x_{4}$ & $x_{5}$ & $x_{6}$ & $x_{7}$ & $x_{8}$ & $x_{9}$ & $x_{10}$ & $x_{11}$ & $x_{12}$ & $x_{13}$ & $x_{14}$ & 2011Q1 & 2011Q2 & 2011Q3 & 2011Q4 \\
\hline 1 & 0 & 1 & 1 & 1 & 1 & 1 & 1 & 1 & 1 & 1 & - & - & - & - & 7.97 & 7.46 & 8.12 & 11.56 \\
\hline 2 & 1 & 0 & 1 & 1 & 1 & 1 & 1 & 1 & 1 & 1 & - & - & - & - & 7.84 & 7.11 & 7.75 & 11.89 \\
\hline 3 & 1 & 1 & 0 & 1 & 1 & 1 & 1 & 1 & 1 & 1 & - & - & - & - & 7.47 & 7.12 & 7.53 & 9.60 \\
\hline 4 & 1 & 1 & 1 & 0 & 1 & 1 & 1 & 1 & 1 & 1 & - & - & - & - & 7.15 & 6.43 & 6.93 & 9.44 \\
\hline 5 & 1 & 1 & 1 & 1 & 0 & 1 & 1 & 1 & 1 & 1 & - & - & - & - & 8.05 & 7.75 & 7.30 & 9.68 \\
\hline 6 & 1 & 1 & 1 & 1 & 1 & 0 & 1 & 1 & 1 & 1 & - & - & - & - & 6.57 & 5.77 & 6.89 & 8.26 \\
\hline 7 & 1 & 1 & 1 & 1 & 1 & 1 & 0 & 1 & 1 & 1 & - & - & - & - & 8.14 & 7.45 & 7.95 & 11.00 \\
\hline 8 & 1 & 1 & 1 & 1 & 1 & 1 & 1 & 0 & 1 & 1 & - & - & - & - & 7.54 & 6.91 & 7.46 & 10.16 \\
\hline 9 & 1 & 1 & 1 & 1 & 1 & 1 & 1 & 1 & 0 & 1 & - & - & - & - & 8.23 & 7.40 & 8.11 & 11.44 \\
\hline 10 & 1 & 1 & 1 & 1 & 1 & 1 & 1 & 1 & 1 & 0 & - & - & - & - & 7.78 & 7.17 & 7.74 & 10.51 \\
\hline 11 & 1 & 1 & 1 & 1 & 1 & 1 & 1 & 1 & 1 & 1 & 0 & 0 & 0 & 0 & 7.47 & 6.86 & 7.39 & 10.05 \\
\hline 12 & 1 & 1 & 1 & 1 & 1 & 1 & 1 & 1 & 1 & 1 & 1 & 0 & 0 & 0 & 6.98 & 6.46 & 6.96 & 9.10 \\
\hline 13 & 1 & 1 & 1 & 1 & 1 & 1 & 1 & 1 & 1 & 1 & 0 & 1 & 0 & 0 & 7.36 & 6.80 & 7.29 & 9.86 \\
\hline 14 & 1 & 1 & 1 & 1 & 1 & 1 & 1 & 1 & 1 & 1 & 0 & 0 & 1 & 0 & 7.46 & 6.86 & 7.39 & 10.02 \\
\hline 15 & 1 & 1 & 1 & 1 & 1 & 1 & 1 & 1 & 1 & 1 & 0 & 0 & 0 & 1 & 7.05 & 6.54 & 7.03 & 9.18 \\
\hline
\end{tabular}

Minimum of relative expected forecast error for reduction decisions is in bold and for expansion decisions is italicized 
to even smaller absolute and relative forecast errors than for the starting portfolio with more product categories. For product categories 3 and 5 the same is true for at least one quarter. Hence, we conclude that horizontal diversification, i.e., product categories 3-6 offering in portfolio, is hardly effective in minimisation of sales risk, measured with relative and absolute errors of sales forecast, and is rationalised with core business strategy alignment decisions but those product categories assortment should be reduced or their product range should be narrowed.

Consistently, expanding portfolio with any of new considered product categories results in more horizontally diversified portfolio and not much lower relative expected error of forecast. Once again, horizontal diversification is ineffective in the minimisation of sales risk.

Results in Table 4 for groups 1, 2, 7-10 and 12-15 concern portfolio concentric diversification that means complementary products of different technology industries offered in the same distribution channel and business's format but mainly to other customers than farmers cultivating crops. The reduction of each of categories $1,2,7-10$ would be ineffective diversification, because it results with a higher relative expected forecast error. Conglomerate diversification is not present in the analysed portfolio. It could be, if the company expands into production, services sectors or customers of branches other than the agricultural one.

A company can simultaneously maximise sales and minimise error of sales forecast, especially, to benefit from smaller safety stock and its smaller costs. Thus we calculated the profitable sales meta-objective according to models (5) and (6) in Table 1. Results for the feasible solutions of portfolios are presented in thousand zloty of profitable sales meta-objective in Table 5. Reading Table 5 we learn for each feasible product portfolio there is forecasted quasi earnings after costs of safety stock keeping in 2011. For starting portfolio 11, that was offered by the company, quarterly forecasted earnings were appropriately 24,544; 27,154; 24,874 and 17,054 thousand zlotys in 2011 following quarters. The last quarter of a year is the worst for agricultural branch, the forecasted earnings equalled to 17,053,540 zloty.

We notice that the higher the sales, the higher the profitable sales and profits too. However, this relation depends on assumed levels of cost parameter $w$ and on inventory service level. We know this due to additional calculations of meta-objective for different values of cost parameter $w$. If service level remains 0.975 and $w=1,5$ than portfolio 6 , so after reduction of very risky product category 6 , becomes more profitable in quarter 4 than starting company's portfolio 11 .

For cost $w=3,5$ portfolio 6 is the most profitable among reduced portfolios and starting portfolio in three out of four quarters. Portfolios 3 and 4 are more profitable in last quarter than starting portfolio 11.

For $w=6$ portfolio 4 and 6 are more profitable than the starting portfolio 11 in all four quarters. This level of $w$ means that if percentage profitability of sales is 5 and percentage cost of safety stock equals 30 , the starting portfolio 11 is less profitable than portfolio 4 and portfolio 6 . Such profit and cost relation is possible for highly differentiated products (Jain and Bala 2018).

Our findings about the diversification influence on profitability are that the higher safety stock costs the more profitable it is to minimise the expected relative error of sales forecast is. If safety stock costs are low relatively to sales profitability it is not 
Table 5 Preview of feasible solutions of model (5): portfolios 1-11 and feasible solutions of model (6): portfolios 11-15 of maximisation of profitable sales meta-objective. We assume that profit per one zloty of sales is the same as cost per one zloty of safety stock, so $w=1$. An inventory service level is assumed to be $97.5 \%$, so critical value for right side of $t$-Student distribution is $t_{\alpha=0.05 ; N-K=24-9=15}=2.13$ and probability of not exceeding it equals $p\left(t_{N-K=15} \leq 2.13\right)=0.975$. Source: own calculation

\begin{tabular}{|c|c|c|c|c|c|c|c|c|c|c|c|c|c|c|c|c|c|c|}
\hline \multirow[t]{3}{*}{ No. } & \multicolumn{14}{|c|}{$x^{\prime}=\left[\begin{array}{ll}x_{1}^{\prime} & x_{2}^{\prime}\end{array}\right]$} & \multirow{2}{*}{\multicolumn{4}{|c|}{$\begin{array}{l}x^{\prime} y_{t}^{*}-w \mathrm{t}_{\alpha, N-K} \sqrt{x^{\prime} V x} \rightarrow \max \\
\text { [thousand zloty] }\end{array}$}} \\
\hline & \multicolumn{10}{|c|}{$\overline{x_{1}^{\prime}=}$} & \multicolumn{4}{|c|}{$x_{2}^{\prime}=$} & & & & \\
\hline & $x_{1}$ & $x_{2}$ & $x_{3}$ & $x_{4}$ & $x_{5}$ & $x_{6}$ & $x_{7}$ & $x_{8}$ & $x_{9}$ & $x_{10}$ & $x_{11}$ & $x_{12}$ & $x_{13}$ & $x_{14}$ & $\overline{2011 Q 1}$ & 2011Q2 & 2011Q3 & 2011Q4 \\
\hline 1 & 0 & 1 & 1 & 1 & 1 & 1 & 1 & 1 & 1 & 1 & - & - & - & - & 21,988 & 23,801 & 21,517 & 13,762 \\
\hline 2 & 1 & 0 & 1 & 1 & 1 & 1 & 1 & 1 & 1 & 1 & - & - & - & - & 22,691 & 25,478 & 23,003 & 13,409 \\
\hline 3 & 1 & 1 & 0 & 1 & 1 & 1 & 1 & 1 & 1 & 1 & - & - & - & - & 22,270 & 23,585 & 22,052 & 16,401 \\
\hline 4 & 1 & 1 & 1 & 0 & 1 & 1 & 1 & 1 & 1 & 1 & - & - & - & - & 21,040 & 23,805 & 21,798 & 15,014 \\
\hline 5 & 1 & 1 & 1 & 1 & 0 & 1 & 1 & 1 & 1 & 1 & - & - & - & - & 18,830 & 19,700 & 21,159 & 15,001 \\
\hline 6 & 1 & 1 & 1 & 1 & 1 & 0 & 1 & 1 & 1 & 1 & - & - & - & - & 21,789 & 25,299 & 20,605 & 16,602 \\
\hline 7 & 1 & 1 & 1 & 1 & 1 & 1 & 0 & 1 & 1 & 1 & - & - & - & - & 21,958 & 24,421 & 22,590 & 15,052 \\
\hline 8 & 1 & 1 & 1 & 1 & 1 & 1 & 1 & 0 & 1 & 1 & - & - & - & - & 23,752 & 26,324 & 24,036 & 16,444 \\
\hline 9 & 1 & 1 & 1 & 1 & 1 & 1 & 1 & 1 & 0 & 1 & - & - & - & - & 21,883 & 24,873 & 22,269 & 14,437 \\
\hline 10 & 1 & 1 & 1 & 1 & 1 & 1 & 1 & 1 & 1 & 0 & - & - & - & - & 23,542 & 25,950 & 23,684 & 16,210 \\
\hline 11 & 1 & 1 & 1 & 1 & 1 & 1 & 1 & 1 & 1 & 1 & 0 & 0 & 0 & 0 & 24,544 & 27,154 & 24,874 & 17,054 \\
\hline 12 & 1 & 1 & 1 & 1 & 1 & 1 & 1 & 1 & 1 & 1 & 1 & 0 & 0 & 0 & 26,965 & 29,508 & 27,035 & 19,591 \\
\hline 13 & 1 & 1 & 1 & 1 & 1 & 1 & 1 & 1 & 1 & 1 & 0 & 1 & 0 & 0 & 25,251 & 27,710 & 25,521 & 17,647 \\
\hline 14 & 1 & 1 & 1 & 1 & 1 & 1 & 1 & 1 & 1 & 1 & 0 & 0 & 1 & 0 & 24,851 & 27,472 & 25,141 & 17,327 \\
\hline 15 & 1 & 1 & 1 & 1 & 1 & 1 & 1 & 1 & 1 & 1 & 0 & 0 & 0 & 1 & 27,324 & 29,813 & 27,417 & 19,873 \\
\hline
\end{tabular}

Maximum of profitable sales meta-objective for reduction decisions is in bold and for expansion decisions is italicized

recommended to minimise expected relative error of sales forecast by product category reduction. Otherwise, some product category reduction can decrease nominal and relative forecast errors but they usually also decrease sales and profits.

\section{Discussion}

The considered conglomeration issue is typical for trading and services businesses. Therefore our model is useful for them but also for production conglomerates that operate many markets and want to balance between their profitability and liquidity performance. Need for such simple and formalized methods was revealed in many surveys on businesses' decision making practices (Carbonell and Rodriguez Escudero 2016; Jugend et al. 2016).

Our product portfolio decision model is based on sales data and analytical concept of risk known from financial methods of product or project decision making. The model is free of high complexity and small reality that according to research conducted by Cooper et al. (1999) are main drawbacks of financial methods 
application. A few simple methods (i.e. NPV, IRR) are popular but omit data interdependency of projects and financial forecasts (Killen 2017). Our model is simple but captures interdependency of products' categories sales data. We have found that the minimisation of sales risk should be measured with relative not nominal error of forecasted sales. Otherwise minimising risk is misunderstood and leads to the reduction of product width in contrary to the concept of product diversification and to unwanted decline in sales and profits. Hence, product category reduction or expansion should be assessed using the following two objectives in our models:

- the minimisation of relative expected error,

- the maximisation of profitable sales' forecast.

Product diversification means the increase of number of product categories or product lines in business's portfolio that results with higher portfolio's sales and their lower variability or risk connected with sales forecasts' errors (Gerchak and He 2003; Gorman and Brannon 2000; Kim et al. 2016; Ton and Raman 2010). It comes true in our research for risk and forecast errors measured in relation to sales, that we find the most appropriate approach, but also for any examined risk measure for product categories that concentrically diversify the portfolio. Hence, concentric diversification is more effective than horizontal one for the control and reduction of market risk of sales. On the other side the more technologically and commercially unrelated to current business added products and markets are, the lower is market risk of sales and business and the higher is operational risk and both affect risk of general performance and profit amount. This our finding is also confirmed by Kim et al. (2016). Also other papers confirm that higher production complexity generates higher operating costs and their risk (Jacobs 2013; Jacobs and Swink 2011). Our research adds to this concept that higher production complexity results with higher sales' risk only if additional products are dedicated to the previous customers of business. This phenomenon is rationalised by us with total sales dependence on one group of customers and their incomes and expenditures fluctuations.

We found how this exclusion of the diversification concept can be easily identified using our model. No matter what measure of the business's risk on the market is used higher product diversity doesn't lower it, if for a considered product category:

- its random, unpredictable deviations of sales are highly positively correlated with sales random deviations of the majority of product categories offered in portfolio, like for product category 6 in Table 2,

- its relative error of sales forecast is higher than for current product portfolio.

In such a special case it is possible that to broaden product portfolio means also to lower business's profit if safety stock costs are relatively high in comparison to sales profitability. If category's sales stimulate risk, destimulate profit, and this category constitutes core business, as category 6 in our research, instead to be fully reduced should go through selective reductions of its products. This finding is consistent with the key conclusion from body of research on merchandise assortment planning (Broniarczyck and Hoyer 2006; Dekimpe et al. 2011; Sloot et al. 2006). 
Our research confirms profit benefits of the selective reductions of the assortment variety of such a product category and shows also risk decrease benefit.

\section{Conclusions}

In the literature of strategic management, marketing and operational management many models of product portfolio are proposed. Those theories in general imply that the higher product diversity or the wider product variety is, the higher is business's operating risk and the lower is business's market risk (Jacobs 2013; Kim et al. 2016; Sun and Govind 2017). However, Sun and Govind (2017) argue that increased product diversification affects positively firm performance and risk if a market is displaying low turbulences. Hence, this paper focuses at formulation and verification of business's risk model for determining expected error of products' and portfolio sales forecast based on sales time series. Operating costs of safety stock keeping are assumed as main benefits of the minimization of product portfolio sales' risk and are estimated in the variant of the model. Sales data of the chosen company is examined for impact of product diversity decisions on firm risk.

Findings confirm common knowledge about sales risk if it is measured relatively to product portfolio sales amount. However findings of the paper give deepen insight in business's risk in relation to product diversity of portfolio and reveal exclusions. These can be of special importance for trading and services companies and other companies that often revise product and market range of their portfolios.

Managers should resign from new products or discontinue to sell offered product categories that if included in business's product portfolio, result with increased operational and technological risk and increased sales risk. Such ineffective product choices are identified in the paper owing to positive correlations of their sales with other products in the portfolio. We rationalize increased relative risk of sales with predominant complement demand relations between products in the portfolio and with business's sales dependence on predominant group of customers and their incomes and expenditures fluctuations.

The model proposed in the paper is useful to assess the impact of selling of given product category on sales risk. Product categories' sales amount and correlations of their random, unpredictable deviations can be measured within portfolio, using the introduced model. It allows to simulate different risk measures of future sales of considered hypothetical product portfolios. Model distinguishes effective product portfolios from ineffective. Furthermore, the optimal product portfolio diversity that minimizes expected sales risk under given constraints is find by solving the model.

There are a few limitations. Findings obtained from the study hold for marginal changes of product portfolio width and diversity. This is well known limitation of every simulation of product decision results under sales dependencies between products (Ailawadi and Keller 2004; Bata et al. 2011; Ton and Raman 2010). Demand limits and relations are dependent on product categories set in product portfolio.

In further works other operating, selling and financial costs of diverse product range in portfolio should be modelled to better assess benefits and disadvantages of sales risk minimization for product portfolio. 
So far operating costs of safety stock keeping has been determined and examined in the paper.

In our model resources limits are taken into account indirectly by constrained number of continued product categories and new product categories in a hypothetical product portfolio. This approach is in accordance with market demand relations because market trends and forecasts of products sales were considered. However, in the further models total costs of product portfolio should be determined and resources limits should be considered in details.

Open Access This article is distributed under the terms of the Creative Commons Attribution 4.0 International License (http://creativecommons.org/licenses/by/4.0/), which permits unrestricted use, distribution, and reproduction in any medium, provided you give appropriate credit to the original author(s) and the source, provide a link to the Creative Commons license, and indicate if changes were made.

\section{References}

Agrawal V, Seshadri S (2000) Impact of uncertainty and risk aversion on price and order quantity in the newsvendor problem. Manuf Serv Oper Manag 2:410-423

Ailawadi KL, Keller KL (2004) Understanding retail branding: conceptual insights and research priorities. J Retail 80(4):331-342

Akkerman R, van Donk DP (2009) Product mix variability with correlated demand in two-stage food manufacturing with intermediate storage. Int J Prod Econ 121(2):313-322

Bandyopadhyay S (2009) A dynamic model of cross-category competition: theory, tests and applications. J Retail 89(4):468-479

Bata SA, Beard J, Egri E, Morris D (2011) Retail revenue management: applying data-driven analytics to the merchandise line of business. J Bus Retail Manag Res 5(2):43-54

Bodie Z, Kane A, Marcus AJ (2009) Investments, 8th edn. McGraw-Hill Irwin, Boston

Broniarczyck SM, Hoyer WM (2006) Retail assortment: more $\neq$ better. In: Kraft M, Mantrala MK (eds) Retailing in the 21st century: current, emerging trends. Springer, Berlin, pp 193-210

Brown JR (2010) Managing the retail format portfolio: an application of modern portfolio theory. J Retail Consum Serv 17(1):19-28

Cadeaux J, Yee L (2013) Performance effect of category assortment and stock allocation decisions for a cash-and-carry wholesaler. Int Rev Retail Distrib Consum Res 23(5):537-552

Carbonell P, Rodriguez Escudero AI (2016) The effects of decentralization in strategy-making and national culture on NPD portfolio planning. J Prod Innov Manag 33(S1):101-116

Chen Y, Krass D (2001) Inventory models with minimal service level constraints. Eur J Oper Res 134(1):120-140

Cooper RG, Edgett SJ, Kleinschmidt EJ (1999) New product portfolio management: practices and performance. J Prod Innov Manag 16(4):333-351

Dekimpe MG, Gielens K, Raju J, Thomas JS (2011) Strategic assortment decisions in information-intensive and turbulent environments. J Retail 87(S):S17-S28

Gerchak Y, He Q-M (2003) On the relation between the benefits of risk pooling and the variability of demand. IIE Trans 35(11):1027-1035

Gorman MF, Brannon JI (2000) Seasonality and the production-smoothing model. Int J Prod Econ 65(2):173-178

Goto H (2008) An optimal portfolio of shelf inventory for SPA shops. Int J Inf Syst Logist Manag 4(1):19-29

Haksever C, Moussourakis J (2005) A model for optimizing multi-product inventory systems with multiple constraints. Int J Prod Econ 97(1):18-30

Hart C, Rafiq M (2006) The dimensions of assortment: a proposed hierarchy of assortment decision making. Int Rev Retail Distrib Consum Res 16(3):333-351 
Hassanzadeh F, Modarres M, Nemati HR (2014) A robust R\&D project portfolio optimization model for pharmaceutical contract research organizations. Int J Prod Econ 158(1):18-27

Hruschka H (2017) Multi-category purchase incidences with marketing cross effects. RMS 11:433-469

Jacobs MA (2013) Complexity: towards the empirical measure. Technovation 33:111-118

Jacobs MA, Swink M (2011) Product portfolio architectural complexity and operational performance: incorporating the roles of learning and fixed assets. J Oper Manag 29(7):677-691

Jain A, Bala R (2018) Differentiated or integrated: capacity and service level choice for differentiated products. Eur J Oper Res 266(3):1025-1037

Jugend D, da Silva SL (2014) Product portfolio management: a framework based on methods, organization, and strategy. Concur Eng Res Appl 22(1):17-18

Jugend D, Silva SL, Salgado MH, Miguel PAC (2016) Product portfolio management and performance: evidence from a survey of innovative Brazilian companies. J Bus Res 69(11):5095-5100

Killen CP (2017) Managing portfolio interdependencies: the effects of visual data representations on project portfolio decision making. Int J Manag Proj Bus 10(4):856-879

Kim J, Lee C-J, Cho Y (2016) Technological diversification, core-technology competence, and firm growth. Res Policy 45(1):113-124

Ma Y, Ailawadi KL, Gauri DK, Grewal D (2011) An empirical investigation of the impact of gasoline prices on grocery shopping behaviour. J Mark 75(2):18-35

Mallin ML, Finkle TA (2011) Apple Inc.: product portfolio analysis. J Int Acad Case Stud 17(7):63-74

Mantrala MK, Levy M, Kahn BE, Fox EJ, Gaidarev P, Dankworth B, Shah D (2009) Why is assortment planning so difficult for retailers? A framework and research agenda. J Retail 85(1):71-83

Markowitz HM (1959) Portfolio selection. Cowles foundation monograph 16. Willey, New York

Mehta N (2007) Investigating consumers' purchase incidence and brand choice decisions across multiple product categories: a theoretical and empirical analysis. Mark Sci 26(2):196-217

Meyvis T, Janiszewski C (2004) When are broad brands stronger brands? An accessibility perspective on the formation of brand equity. J Consum Res 31(2):346-357

Oh J, Yang J, Lee S (2012) Managing uncertainty to improve decision-making in NPD portfolio management with a fuzzy expert system. Expert Syst Appl 39(10):9868-9885

Radasanu AC (2016) Inventory management, service level and safety stock. J Public Adm Finance Law 9:145-153

Rajaram K (2001) Assortment planning in fashion retailing: methodology, application and analysis. Eur J Oper Res 129(1):186-208

Rosenbloom B (1980) Strategic planning in retailing: prospects and problems. J Retail 56(1):107-120

Sloot LM, Fok D, Verhoef PC (2006) The short and long-term impact of an assortment reduction on category sales. J Mark Res 43(4):536-548

Statistics Poland (2005-2011) Sources materials, production of major industrial products in months from I.2005-XII.2011, statistical agency "Statistics Poland" reports, Warsaw. Available at http://www. stat.gov.pl/en/topics

Statistics Poland (2012) Agriculture in 2011, Statistical Year Book of government agency, Statistics Poland, Warsaw

Sun G, Govind R (2017) Product market diversification and market emphasis: impacts on firm idiosyncratic risk in market turbulence. Eur J Mark 51(7/8):308-1331

Ton Z, Raman A (2010) The effect of product variety and inventory levels on retail store sales: a longitudinal study. Prod Oper Manag 19(5):546-560

Trappey CV, Trappey AJ, Feinberg R (1993) Planning product assortment using portfolio optimization. In: Fandel G, Gulledge T, Jones A (eds) Operations research in production planning and control. Springer, Berlin, pp 3-20

Vaagen H, Wallace SW (2008) Product variety arising from hedging in the fashion supply chains. Int J Prod Econ 114(2):431-455

Voss M (2012) Impact of customer integration on project portfolio management and its success-developing a conceptual framework. Int J Proj Manag 30(2012):567-581

Wan X, Dresner MF, Evers PT (2014) Assessing the dimensions of product variety on performance: the value of product line and pack size. J Bus Logist 35(3):213-224 